\title{
ZEROS OF CERTAIN POLYNOMIALS AND ANALYTIC FUNCTIONS WITH RESTRICTED COEFFICIENTS
}

\author{
IRshad AHMAD, TAWHEEDA RASOOL AND ABDUl Liman
}

\begin{abstract}
In this paper, we consider the problem of finding the number of zeros of a special class of polynomial functions and functions analytic in a prescribed region by subjecting the real and imaginary parts of its coefficients to certain restrictions.
\end{abstract}

Mathematics subject classification (2010): 30A01, 30C10, 30C15.

Keywords and phrases: Zeros, polynomial, prescribed region.

\section{REFERENCES}

[1] A. Aziz And Q. G. Mohammad, Zero Free Regions for Polynomials and Some Generalizations of Eneström-Kakeya Theorem, Canadian Mathematical Bulletin, 27 (1984), 265-272.

[2] K. K. Dewan, Extremal Properties and Coefficient Estimates for Polynomials with Restricted Zeros and on Location of Zeros of Polynomials, Ph. D Thesis, IIT Delhi, 1980.

[3] E. Egervary, On a Generalization of a Theorem of Kakeya, Acta Mathematica Scientia, 5 (1931), $78-82$.

[4] N. K. Govil And Q. I. Rahman, On the Eneström Kakeya Theorem, Tohoku Math. J., 20 (1968), 126-136.

[5] S. KAKEYA, On the limits of the roots of an algebraic equation with positive coefficients, Tohoku Math. J., 2 (1912-13), 140-142.

[6] M. Marden, The Geometry of Polynomials, Amer. Math. Monthly, 83 (10) (1997), 788-797.

[7] Q. G. Mohammad, On the zeros of the polynomials, Amer. Math. Monthly, 72 (6) (1965), 631-633.

[8] Q. I. Rahman AND G. SchmeIsser, Analytic Theory of Polynomials, Oxford Univ. Press, 2002.

[9] W. M. Shah And A. Liman, On Eneström Kakeya Theorem and Related Analytic Functions, Proc. Indian Acad. Sci. (Math Sci.), 117 (3) (2007), 359-370.

[10] E. C. Titchmarsh, The theory of functions, $2^{\text {nd }}$ ed. Oxford Univ. Press, London, (1939).

[11] C. M. Upadhye, On the zeros of a polynomial, Theory of Polynomials and Applications, Deep and Deep Publications, 2007, 197-202. 